\title{
Aplikasi Game Catur Multiplayer Via Bluetooth Berbasis Android
}

\author{
Multiplayer Chess Game Via Android-Based Bluetooth App
}

\author{
Puja Mangunsong ${ }^{1}$, Lili Tanti ${ }^{2}$, Rofiqoh Dewi ${ }^{3}$ \\ Program Studi Teknik Informatika, Universitas Potensi Utama (UPU) \\ Jl. K.L. Yos Sudarso Km. 6,5 No. 3A, Medan (20241) \\ e-mail: pujamopo09@gmail.com
}

\begin{abstract}
Chess game is a strategy game that can improve human intelligence. In this game required a strategy used to attack and survive in order to win the game. This game is played by two people. In the process each player determines the best step of each chess piece in order to win the game. In general, in the game of chess required chess board size is large and not a natural thing if taken everywhere. Therefore the authors will duplicate a chess game app that can be played using android smartphone. In the process of playing chess then will use two android smartphone that will connect with bluetooth connection. In making this game chess used android software so as to produce the final result will be used on android smartphone. Chess game application is expected to facilitate every user to be able to play chess games anywhere and anytime easily.
\end{abstract}

Keywords: Games, Chess, Bluetooth, Smartphone, Android

\begin{abstract}
Abstrak
Permainan catur adalah permainan strategi yang dapat meningkatkan kecerdasan manusia. Pada permainan ini diperlukan strategi yang digunakan untuk menyerang dan bertahan agar dapat memenangkan permainan. Permainan ini dimainkan oleh dua orang. Dalam prosesnya masing-masing pemain menentukan langkah terbaik setiap bidak catur agar dapat memenangkan permainan. Pada umumnya dalam memainkan permainan catur dibutuhkan papan catur yang ukurannya cukup besar dan tidak merupakan hal yang wajar jika dibawa kemana-mana. Oleh sebab itu penulis akan merancang sebuah aplikasi permainan catur yang dapat dimainkan menggunakan smartphone android. Dalam proses bermain catur selanjutnya akan menggunakan dua buah smartphone android yang akan dihubungkan dengan koneksi bluetooth. Dalam pembuatan permainan catur ini digunakan perangkat lunak android studio sehingga hasil akhirnya akan dapat digunakan pada smartphone android. Aplikasi permainan catur ini diharapkan akan memudahkan setiap pengguna untuk dapat bermain game catur dimana saja dan kapan saja dengan mudah.
\end{abstract}

Kata kunci : Permainan, Catur, Bluetooth, Smartphone, Android 


\section{PENDAHULUAN}

Game merupakan sebuah permainan yang sangat menghibur bagi kita yang bosan atau jenuh akan kegiatan sehari-hari. Dalam sebuah game melibatkan stimulasi mental atau fisik, dan terkadang kedua-duanya. Game merupakan sesuatu hal yang dimainkan dengan suatu aturan tertentu yang bias digunakan untuk tujuan kesenangan dan terkadang digunakan untuk tujuan pendidikan.

Oleh Karena itu perkembangan dunia game sekarang ini sangatlah cepat baik itu dalam perangkat khusus buat game, komputer $(P C)$, ataupun Handphone $(H P)$. Permainan catur merupakan suatu model perang di atas papan catur (Harun, 1985:28). Membicarakan tentang teknologi mobile sekarang ini tentu amat menyenangkan. Ini Karena perkembangan device mobile sangat cepat dan menarik. Salah satunya device android. Perkembangan android yang cepat ini selain Karena kecanggihanya juga Karena android merupakan system operasi mobile yang gratis dan open source atau kode sembernya terbuka. Android adalah sistem operasi untuk telepom seluler yang berbasis Linux, Android menyediakan platform yang bersifat open source bagi para pengembang untuk menciptakan sebuah aplikasi (Safaat, 2011). permainan catur merupakan permainan pikiran yang dimainkan oleh dua orang, dalam permainan ini para pemainnya dituntut untuk berpikir ekstra dan memiliki kejelian untuk dapat menguasai permainan, membaca karakteristik lawan dan memperhitungkan dengan jeli tiap langkah yang akan diambil (Alit Prajatama, 2015). Seiring perkembangan zaman banyak game tradisional mulai ditinggalkan dan terganti dengan game baru yang lebih menarik dan canggih.

Dengan perlahan-lahan tergesernya game tradisional dengan game modern maka alat dari game tradisional juga sulit untuk dicari di toko permainan. Masyarakatpun kesulitan untuk bermain maupun mendapatkan peralatan game tradisional. Maka dari itu penulis ingin mengenalkan kembali game tradisional catur dalam bentuk game mobile dengan menggunakan tampilan yang lebih menarik dan modern serta terdapat nilai tradisional dibandingkan dengan game yang sudah ada yang menampilkan permainan dalam bentuk fisik. Game mobile saat ini sedang digemari oleh masyarakat, Karena dapat dimainkan dimana saja dan lebih mudah didapatkan. Akan tetapi, apa yang di tawarkan oleh game disini adalah memperkenalkan konsep terhadap permainan tradisional catur, kemampuan pemecah masalah dalam permainan catur ini, dan pertisipasi praktis. Berdasarkan alasan tersebut penulis berkeinginan untuk membangun sebuah system berupa aplikasi mobile berbasis android. Oleh Karena itu, judul yang akan diambil oleh penulis ialah "Aplikasi Game Catur Multiplayer Via Bluetooth Berbasis Android".

\section{METODE PENELITIAN}

Untuk dapat mengimplementasikan sistem di atas, maka secara garis besar digunakan beberapa metode sebagai berikut:

A. Metode Pengumpulan Data

Sistem yang dirancang tentunya memerlukan pengumpulan data, dalam proses pengumpulan data terdapat beberapa cara, berikut diantaranya :

1. Studi Literatur, dengan cara mempelajari buku-buku acuan dan literatur yang berhubungan dengan materi dalam penulisan skripsi.

2. Pengamatan, yaitu pengumpulan data dan informasi yang dilakukan dengan cara pengamatan langsung aplikasi permainan catur yang sudah ada.

3. Wawancara, yaitu pengumpulan data dengan cara melakukan tanya jawab dengan instansi atau orang yang mengerti peraturan permainan catur. 
4. Web Browsing, yaitu penulis mencari data-data yang mendukung penulisan skripsi melalui internet.

B. Metode perancangan sistem

Langkah-langkah yang diperlukan untuk mencapai tujuan perancangan dapat dilihat pada gambar 1.

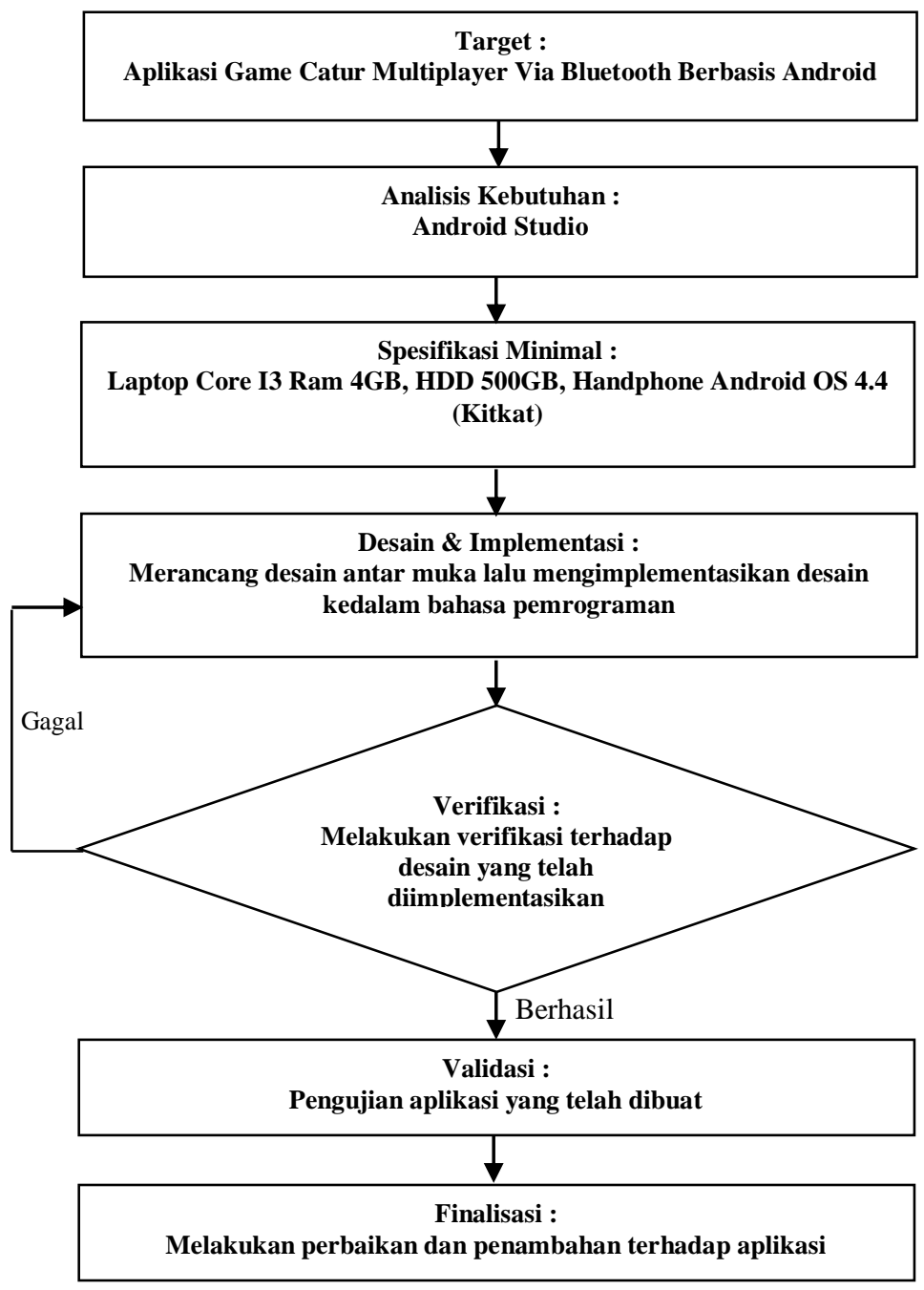

Gambar 1. Prosedur Perancangan

1. Analisis Kebutuhan

Setelah melalui tahap prosedur perancangan, maka tahap selanjutnya adalah analisa kebutuhan yaitu hal-hal yang diperlukan untuk perancangan sistem berupa perangkat lunak dan perangkat keras yang dibutuhkan untuk membangun aplikasi.

a. Spesifikasi

Dalam membuat skripsi ini, spesifikasi dari perangkat keras (Hardware) dan perangkat lunak (Software) yang digunakan adalah :

1) Perangkat Keras (Hardware)

Perangkat keras yang digunakan antara lain :

a) Laptop : Core i3 Processor

b) Hard disk : $500 \mathrm{~GB}$

c) RAM 4 GB 
2) Perangkat lunak (Software)

Software yang digunakan untuk membuat skripsi ini antara lain :

a) Sistem operasi Windows 7

b) Android Studio

b. Desain dan Implementasi

Pada tahap ini dirancang sebuah desain antar muka dari aplikasi game catur multiplayer via bluetooth berbasis android. Bagaimana desain yang akan digunakan pada antarmuka perangkat android. Setelah dilakukan perancangan desain aplikasi selanjutnya melakukan implementasi terhadap desain yang telah dirancang kedalam bahasa pemrograman.

c. Verifikasi

Verifikasi dilakukan untuk memeriksa ulang apakah aplikasi telah dibuat sesuai dengan apa yang direncanakan dalam perancangan yang akan digunakan dalam pembuatan aplikasi ini. Apakah desain yang dirancang dapat diimplementasikan kedalam bahasa pemrograman.

\section{d. Validasi}

Pada tahap ini dilakukan pengujian aplikasi game catur multiplayer via bluetooth berbasis android secara menyeluruh, meliputi pengujian fungsional dan pengujian ketahanan aplikasi. Pengujian fungsional dilakukan untuk mengetahui bahwa aplikasi game catur multiplayer via bluetooth berbasis android telah berjalan dengan sesuai dengan perancangan. Pengujian ketahanan merupakan kemampuan aplikasi untuk berjalan dengan baik pada spesifikasi minimum komputer sesuai dengan yang telah dicantumkan.

\section{HASIL DAN PEMBAHASAN}

31. Desain Sistem

Desain system secara global menggunakan Bahasa pemodelan UML yang terdiri dari Usecase Diagram, Activity Diagram, dan sequence Diagram.

\subsubsection{Use-case Diagram}

Use Case Mendeskripsikan sebuah interaksi antara satu atau lebih aktor dengan sistem informasi yang akan dibuat. Dapat dikatakan Use Case digunakan untuk mengetahui fungsi apa saja yang berhak menggunakan fungsi-fungsi tersebut.

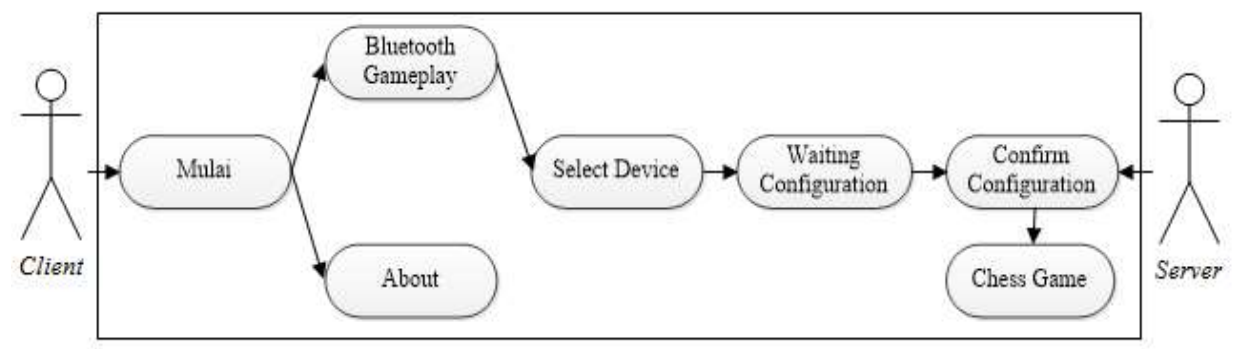

Gambar 2. Use Case Diagram Aplikasi Game Catur

\subsubsection{Activity Diagram Gampe Play}

Activity Diagram menggambarkan berbagai alir aktivitas dalam sistem yang sedang dirancang, bagaimana masing-masing alir berawal, decision yang mungkin terjadi, dan bagaimana mereka berakhir. Activity Diagram juga dapat menggambarkan proses paralel yang mungkin terjadi pada beberapa eksekusi. Activity Diagram merupakan state diagram khusus, di mana 
sebagian besar state adalah action dan sebagian besar transisi di-trigger oleh selesainya state sebelumnya (internal processing). Oleh karena itu activity diagram tidak menggambarkan behaviour internal sebuah sistem (dan interaksi antar subsistem) secara eksak, tetapi lebih menggambarkan proses-proses dan jalur-jalur aktivitas dari level atas secara umum.

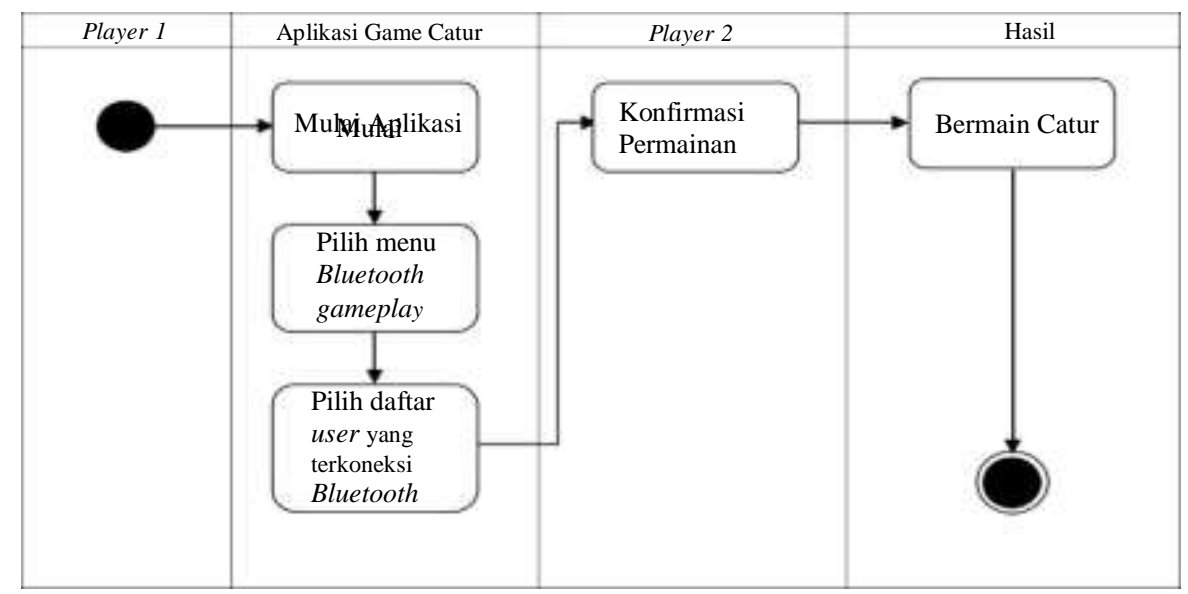

Gambar 3. Activity Diagram Bluetooth Gameplay

\subsubsection{Activity Diagram About}

Activity diagram about menggambarkan alir aktifitas pada saat user memilih menu about pada aplikasi. Activity diagram about dapat dilihat pada gambar 4 berikut ini:

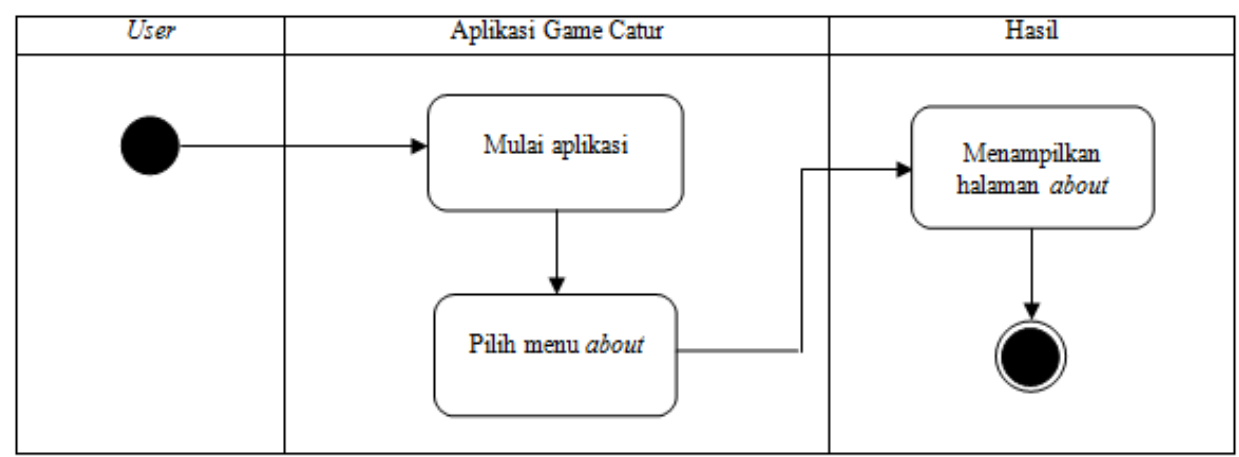

Gambar 4. Activity Diagram About

\subsubsection{Sequence Diagram Game Play}

Sequence Diagram (diagram urutan) adalah suatu Diagram yang memperlihatkan atau menampilkan interaksi-interaksi antar objek di dalam sistem yang disusun pada sebuah urutan atau rangkaian waktu. Interaksi antar objek tersebut termasuk pengguna, display, dan sebagainya berupa message (pesan). Sequence Diagram digunakan untuk menggambarkan skenario atau rangkaian langkah-langkah yang dilakukan sebagai sebuah respon dari suatu event (kejadian) untuk menghasilkan output tertentu. Sequence Diagram diawali dari apa yang me-trigger aktivitas tersebut, proses dan perubahan apa saja yangterjadi secara internal dan output apa yang dihasilkan. 


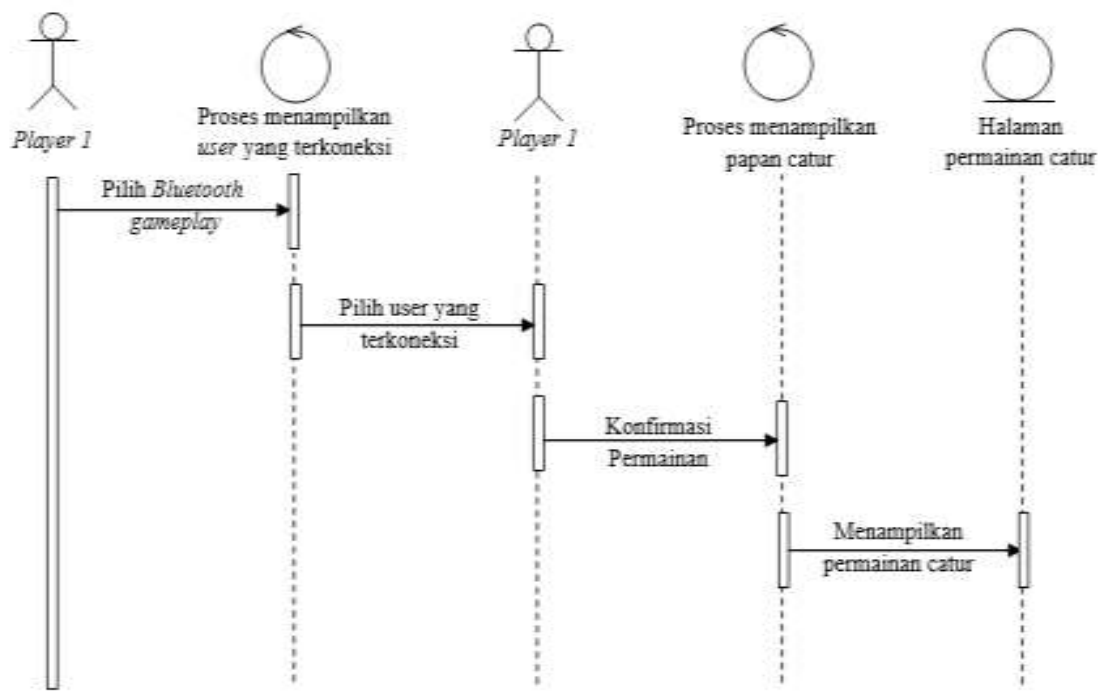

Gambar 5. Sequence Diagram Bluetooth Gameplay

\subsubsection{Sequence Diagram About}

Sequence diagram about menggambarkan interaksi yang terjadi pada saat memilih menu about untuk menampilkan informasi mengenai aplikasi game catur. Sequence diagram about ditunjukkan pada gambar 6:

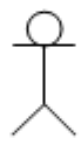

User

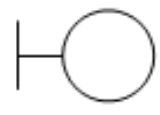

Halaman about

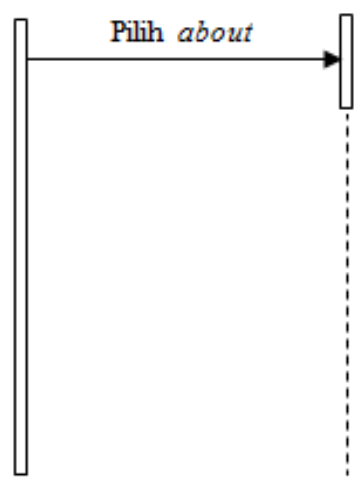

Gambar 6. Sequence Diagram About

\subsection{Hasil Dan Uji Coba}

akan dijelaskan tampilan hasil dari aplikasi yang telah dibuat, yang digunakan untuk memperjelas tentang tampilan-tampilan yang ada pada aplikasi game catur multiplayer via bluetooth berbasis android. Sehingga hasil implementasinya dapat dilihat sesuai dengan hasil program yang telah dibuat. Dibawah ini akan dijelaskan tiap-tiap tampilan yang ada pada program.

1. Uji Coba Aplikasi

Aplikasi ini akan dijalankan pada smartphone android dengan sistem operasi minimal 4.4 (Kitkat). Aplikasi ini dirancang menggunakan perangkat lunak Android Studio dengan bahasa pemrograman java.

2. Rancangan Tampilan Desain Halaman Utama

Merupakan tampilan rancangan halaman utama saat dijalankan. Adapun keterangannya sebagai berikut : 
a) Menu untuk bermain catur melawan user lain menggunakan koneksi bluetooth.

b) Menu untuk menampilkan halaman about.

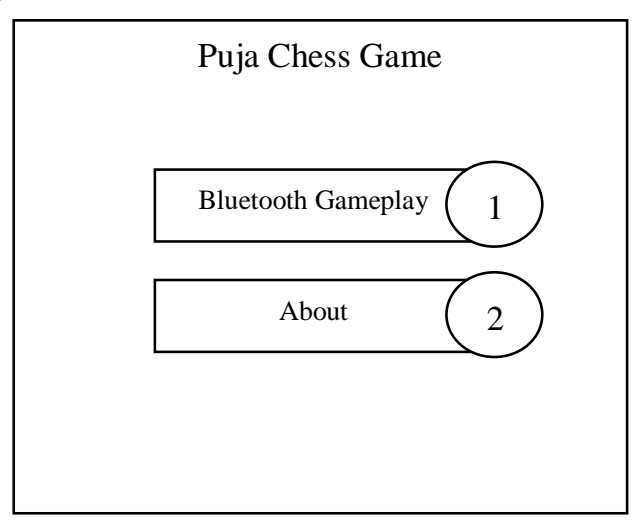

Gambar 7. Rancangan Tampilan Desain Halaman Utama

3. Tampilan Desain Form Halaman Permainan Catur

Keterangan tampilan halaman permainan catur, yaitu :

a) Menampilkan papan catur untuk bermain melawan user melalui koneksi Bluetooth pada smartphone.

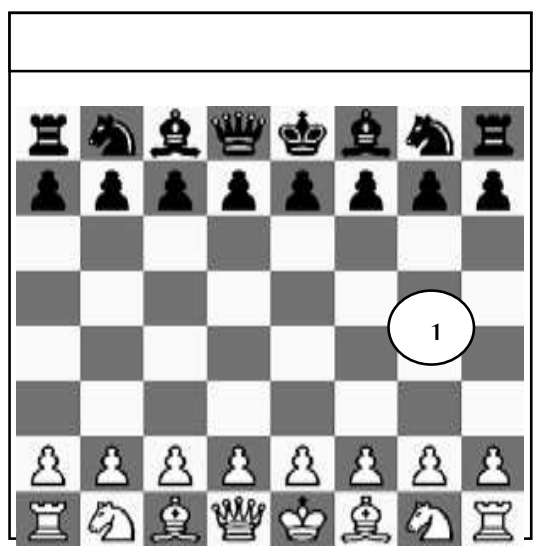

Gambar 8. Rancangan Tampilan Desain Form Halaman Permainan Catur

\section{Tampilan Halaman Utama}

Pada halaman ini user dapat memilih untuk memulai permainan catur dengan koneksi bluetooth atau melihat informasi tentang aplikasi. Gambar tampilan halaman utama ditunjukkan pada gambar 9 .

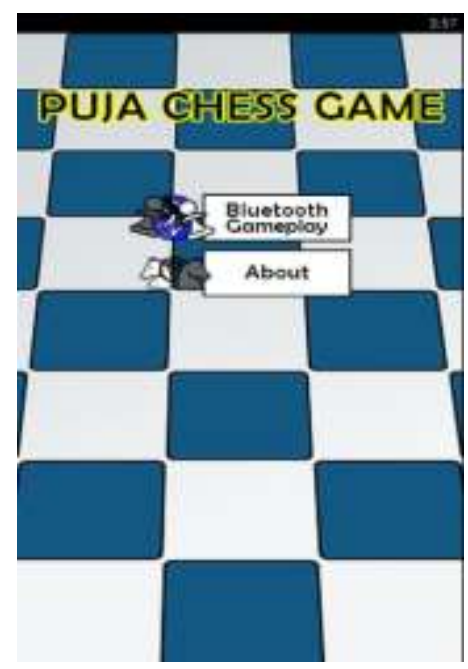

Gambar 9. Tampilan Halaman Utama 
5. Tampilan Halaman Daftar Perangkat

Pada halaman ini akan ditampilkan perangkat user yang tersedia untuk dikoneksikan dengan bluetooth agar dapat memulai permainan catur. Gambar tampilan daftar perangkat ditunjukkan pada gambar 10 .

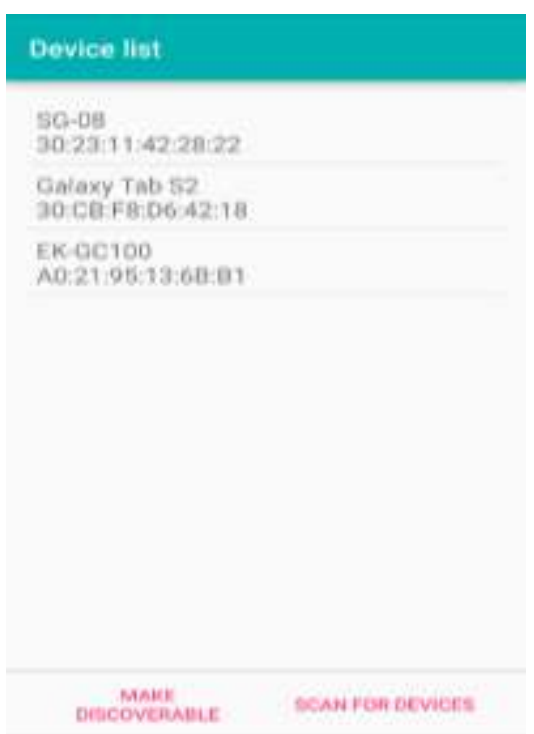

Gambar 10. Tampilan Halaman Daftar Perangkat

6. Tampilan Halaman About

Tampilan ini digunakan untuk menampilkan judul skripsi dari program yang dibuat dan juga menampilkan nama dari pembuat skripsi. Gambar tampilan halaman about ditunjukkan pada gambar 11

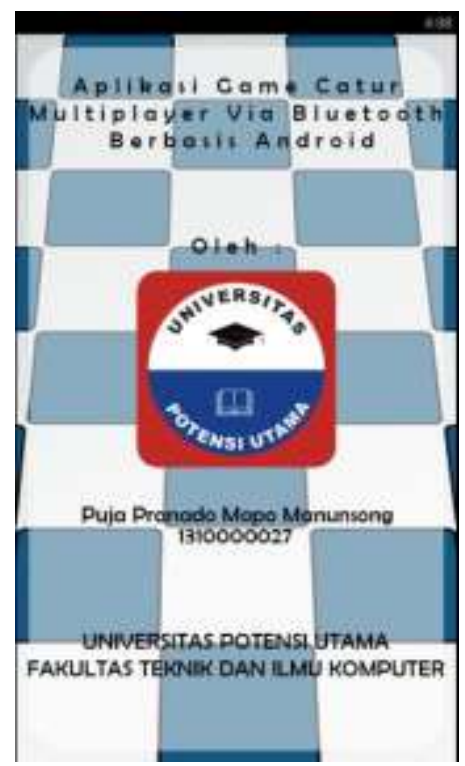

Gambar 11. Tampilan Halaman About

\subsection{Kelebihan dan Kekurangan}

Kelebihan dan kekurangan dari hasil rancangan tentang aplikasi game catur multiplayer via bluetooth berbasis android yang telah dibangun dapat penulis simpulkan sebagai berikut : 
1. Kelebihan Aplikasi

a. Aplikasi ini dapat memainkan permainan catur secara multiplayer memanfaatkan dua buah smartphone android.

b. Aplikasi ini hanya membutuhkan koneksi bluetooth untuk melakukan permainan catur antara dua buah smartphone android.

c. Pada aplikasi ini juga dapat mengaktifkan bluetooth secara langsung sehingga tidak perlu masuk ke pengaturan smarphone untuk mengaktifkan bluetooth.

d. Terdapat fitur undo (membatalkan langkah) pada permainan catur untuk pemain yang sedang belajar bermain catur.

2. Kekurangan dari aplikasi yang dirancang :

a. Aplikasi ini hanya dapat digunakan pada smartphone android saja.

b. Belum ada fitur untuk bermain melawan komputer maupun bermain menggunakan satu smartphone saja.

c. Tidak ada pilihan lanjutan setelah permainan catur selesai jika salah satu pemain telah melakukan "skak mat".

d. Jarak yang didukung untuk bermain disesuaikan dengan jarak koneksi bluetooth pada masing-masing perangkat.

e. Tidak terdapat perhitungan bidak yang telah "dimakan” pada papan permainan catur.

\section{KESIMPULAN}

Berdasarkan hasil pambahasan dan uji coba yang telah dilakukan, dapat disimpulkan :

a. Aplikasi ini dapat digunakan untuk bermain catur menggunakan dua buah smartphone android secara multiplayer.

b. Aplikasi ini dapat dijalankan dengan baik pada smartphone android tanpa force close.

c. Fitur bluetooth dapat diaktifkan secara langsung menggunakan aplikasi ini.

d. Bidak catur dapat digerakkan sesuai dengan langkahnya masing-masing.

e. Setelah melakukan skak mat, bidak catur tidak dapat digerakkan lagi.

\section{SARAN}

Untuk menyempurnakan aplikasi ini maka diberikan saran :

a. Diharapkan aplikasi ini dikembangkan sehingga dapat digunakan pada perangkat dengan sistem operasi IOS dan Windows.

b. Diharapkan terdapat fitur lanjutan saat permainan selesai seperti mengulangi permainan, kembali ke menu awal atau keluar dari aplikasi.

c. Diharapkan terdapat fitur untuk menghitung bidak catur yang telah dimakan.

\section{UCAPAN TERIMA KASIH}

Penulis mengucapkan terimakasih kepada staf dan pegawai Universitas Potensi Utama yang telah memberi dukungan terhadap penelitian ini. 


\section{DAFTAR PUSTAKA}

[1]Harun, 1985:28, "Pengertian Papan Catur", Sentra Penelitian Engineering dan Edukasi. 4. 3845

[2]Safaat, 2011, “Manfaat Dari Operasi Sistem Android ”, 190 CSRID Journal. 7. 190-200.

[3] Alit Prajatama, 2015, “Aplikasi Multimedia Pembelajaran Interaktif Strategi Permainan Catur”, Jurnal Sistem dan Informatika. 9. 24-35. 